\title{
EXTRATORES DE CÁPSULAS POROSAS PARA O MONITORAMENTO DA CONDUTIVIDADE ELÉTRICA E DO TEOR DE POTÁSSIO NA SOLUÇÃO DE UM SOLO
}

\author{
Ênio Farias de França e Silva ${ }^{1,5 *}$; Gláucia Regina Anti2,6; Quirino Augusto de Camargo Carmello3; \\ Sérgio Nascimento Duarte ${ }^{4}$ \\ ${ }^{1}$ Pós-Graduando do Depto. de Engenharia Rural - USP/ESALQ. \\ ${ }_{3}^{2}$ Pós-Graduanda do Depto. de Solos e Nutrição de Plantas - USP/ESALQ. \\ ${ }^{3}$ Depto. de Solos e Nutrição de Plantas - USP/ESALQ, C.P. 9 - CEP:13418-900 - Piracicaba, SP. \\ ${ }^{4}$ Depto. de Engenharia Rural - USP/ESALQ. \\ ${ }^{5}$ Bolsista CAPES. \\ ${ }^{6}$ Bolsista FAPESP. \\ *Autor correspondente <effsilva@carpa.ciagri.usp.br>
}

RESUMO: Este trabalho teve como objetivo avaliar a utilização de extratores de cápsulas porosas no monitoramento da condutividade elétrica e da concentração de potássio na solução do solo, em uma área cultivada com tomates e fertirrigada com três níveis de potássio e frequências de aplicação de um e três dias. Os valores de condutividade elétrica e concentração de potássio encontrados na solução do solo foram corrigidos para a umidade da pasta saturada, em função das diferentes umidades do solo no momento da extração. Os valores de condutividade elétrica obtidos com os extratores de cápsulas porosas e corrigidos para a umidade da pasta subestimaram os medidos no extrato da pasta saturada em torno de $16 \%$. Para as concentrações de potássio, a mesma tendência foi observada, sendo a magnitude cerca de $10 \%$. Os coeficientes de determinação $\left(R^{2}\right)$ foram superiores a 0,7 para as duas variáveis analisadas. A condutividade elétrica e a concentração de potássio podem ser avaliadas utilizando-se extratores de solução, com precisão razoável.

Palavras-chave: cápsulas porosas, condutividade elétrica, potássio, fertirrigação

\section{POROUS CERAMIC CUP EXTRACTORS TO MONITOR ELECTRIC CONDUCTIVITY AND POTASSIUM LEVELS IN SOIL SOLUTION}

\begin{abstract}
The objective of this work was to evaluate porous ceramic cups to observe electric conductivity and potassium concentration in soil solution. An area cultivated with tomatoes under fertirrigation with three potassium levels and application frequencies of one and three days, was used. Values for electric conductivity and $\mathrm{K}$ concentration were corrected for moisture using saturated pastes as a function of different soil moistures. Values for electric conductivity obtained with porous ceramic cups underestimated by approximately $16 \%$ these characteristics measured in the saturation paste extract. The same tendency was observed in the $K$ concentrations, being underestimated by approximately $10 \%$. Coefficients of variation $\left(R^{2}\right)$ were greater by 0.7 for the two analyzed variables. Results showed that electric conductivity and K concentration can be analyzed through the solution extractors with an acceptable precision.

Key words: ceramic cups, electric conductivity, potassium, fertirrigation
\end{abstract}

\section{INTRODUÇÃO}

O conhecimento da composição química da solução do solo, bem como da condutividade elétrica é importante para verificar a disponibilidade de nutrientes, determinar o potencial osmótico e até a presença de íons tóxicos, ao longo do ciclo de uma cultura. Entretanto, a amostragem e a realização de análise periódica de solo, com a finalidade de acompanhar as concentrações dos íons na solução, durante as fases de crescimento e desenvolvimento da cultura são inviáveis economicamente em uma atividade agrícola comercial, além de não ser uma metodologia instantânea, que possibilita tomadas de decisão imediatas. $O$ extrator de solução é uma alternativa capaz de solucionar o problema de forma eficaz e a um baixo custo, principalmente se associado a determinações rápidas em campo.

A quantificação da condutividade elétrica do extrato de saturação (CEes) é mais evidenciada na literatura que as medidas de condutividade elétrica obtidas por outras metodogias. A tolerância de diferentes culturas ao efeito da salinidade do solo é expressa em diversas publicações por intermédio de valores de CEes. Pode-se destacar os valores de salinidade limiar publicados em trabalhos científicos como os de Maas \& Hoffman (1977); Ayers (1977); Maas (1984); Tanji (1990) e Ayers \& Westcot (1991). De acordo com Richards (1954), a alteração da condutividade elétrica é um reflexo da mudança no teor 
de água e/ou diluição da solução do solo. Assim, os resultados de condutividade elétrica verificados na solução do solo podem ser estimados na saturação, sendo corrigidos em função das diferentes umidades.

Burgueño (1996) sugere o monitoramento da salinidade, ou seja, da concentração iônica por intermédio de medidas sistemáticas da condutividade da solução do solo e até mesmo a tomada de decisão quanto ao momento e quantidade de fertilizantes a serem aplicados via água de irrigação. Para a cultura do tomate delimita valores de condutividade elétrica na solução do solo entre 0,8 a 1,0 e 1,5 a $2,5 \mathrm{dS} \mathrm{m}^{-1}$ durante as fases de crescimento e desenvolvimento, respectivamente. $\mathrm{O}$ autor cita ainda que a concentração de potássio na solução do solo deve ser superior a $3,9 \mathrm{mmol}_{\mathrm{c}} \mathrm{L}^{-1}$.

O objetivo deste trabalho foi avaliar a possibilidade da utilização de extratores de cápsulas porosas no monitoramento da condutividade elétrica e da concentração de potássio na solução do solo.

\section{MATERIAL E MÉTODOS}

O experimento de campo foi realizado em Piracicaba, na Escola Superior de Agricultura "Luiz de Queiroz", a $22^{\circ} 42^{\prime}$ de latitude sul, $47^{\circ} 38^{\prime}$ de longitude oeste e a uma altitude de $546 \mathrm{~m}$, em um solo classificado como Terra Roxa Estruturada, durante o período compreendido entre os meses de maio e agosto do ano de 1999. Utilizaram-se, no transplante, mudas de tomates da variedade Carmem com 30 dias de germinadas, plantadas num espaçamento de $0,8 \times 1,5 \mathrm{~m}$, sendo tutoradas conforme técnicas inerentes à variedade.

As aplicações de fertilizantes foram realizadas via água de irrigação com uma freqüência de um e três dias. As quantidades destes fertilizantes e a calagem foram recomendadas segundo Trani et al. (1996), tendo o potássio variado em 50, 100 e $150 \%$ da recomendação, correspondendo a 190, 380 e $570 \mathrm{~kg} \mathrm{ha}^{-1}$ de potássio.

Os extratores de cápsulas porosas foram instalados a uma distância de $10 \mathrm{~cm}$ em relação à planta de tomate e com a cápsula a $20 \mathrm{~cm}$ de profundidade em relação à superfície do solo. Em direção oposta à planta com distância e profundidade equivalentes foram inseridos no solo tensiômetros, com a finalidade de verificar indiretamente o potencial da água do solo no momento da extração.

O conhecimento da umidade do solo no momento da extração é importante, pois possibilita estimar a condutividade elétrica e a concentração de íons em uma umidade padrão ou predeterminada. A curva de retenção de água no solo (Figura 1) foi determinada através de uma regressão exponencial dos resultados obtidos em laboratório, utilizando-se amostras de solo indeformadas e funis de placa porosa conforme a metodologia proposta por Haines (1930) nas tensões de $1,2,4,10,30$ e $50 \mathrm{kPa}$.

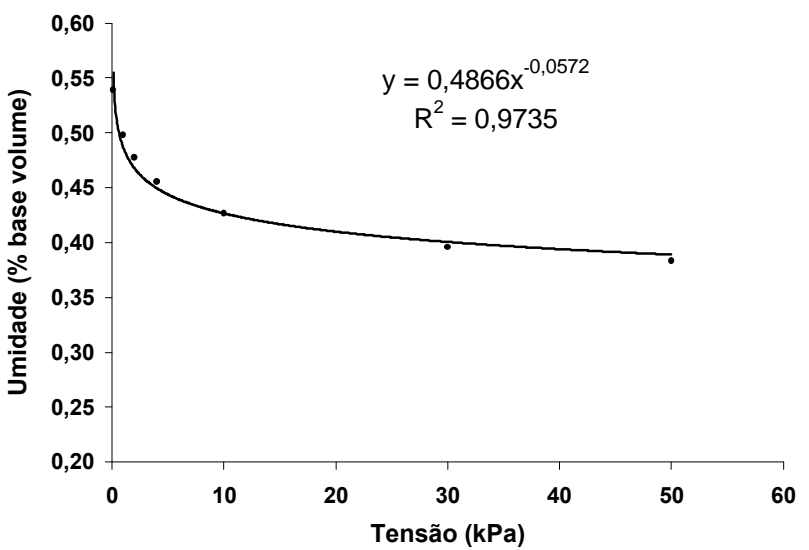

Figura 1 - Curva de retenção da água no solo.

Os extratores de solução possuíam na sua extremidade inferior cápsulas porosas de cerâmica de 20 $\mathrm{mm}$ de diâmetro e $50 \mathrm{~mm}$ de comprimento. As cápsulas foram anteriormente testadas quanto a uma possível contaminação da solução por sais, visto que alguns resíduos poderiam estar presentes nos poros ou ainda, quanto a uma redução na concentração iônica ocasionada por adsorção de íons como cita Grover \& Lamborn (1970).

Os extratores de cápsulas porosas foram submetidos a um vácuo de aproximadamente $72 \mathrm{kPa}$ por um período de sete dias, quando eram coletadas as soluções e aplicado um novo vácuo em um procedimento subsequente, tendo assim, uma frequência semanal no processo de extração. As leituras de tensão com finalidade de verificar os níveis de umidade do solo foram realizadas no momento em que se aplicava o vácuo nos extratores. Esta decisão foi tomada em virtude da pequena variação de umidade do solo, dada a alta frequência de irrigação, além de que, o maior volume de solução do solo succionado para o interior do extrator dá-se logo após a aplicação do vácuo.

Durante a última extração da solução foram retiradas amostras de solo, nos locais onde encontravamse instalados os extratores, com a finalidade de comparar os valores obtidos com os extratores de cápsula com o método padrão, ou seja, o da pasta saturada. Utilizando 250 gramas dessas amostras de solo seco ao ar e peneirado em peneiras de $2 \mathrm{~mm}$, prepararam-se pastas saturadas, as quais foram colocadas em repouso por um período de 24 horas de acordo com a metodologia proposta por Richards (1954). Em seguida, retirou-se por meio de sucção a valores próximos a $100 \mathrm{kPa}$ os extratos saturados, nos quais foram medidas a condutividade elétrica e a concentração de potássio. A umidade de saturação determinada nessa ocasião por gravimetria resultou em um valor de 40,1\%.

Os valores de condutividade elétrica e concentração de potássio obtidos na solução do solo por meio dos extratores foram corrigidos para a umidade de saturação, a fim de poder comparar-se, por intermédio de correlação, com os medidos no extrato da pasta saturada. 
Os valores corrigidos foram denominados condutividade elétrica do extrato de saturação estimada e concentração de potássio no extrato de saturação estimada. A correção foi realizada por meio das equações (1) e (2):

$$
\begin{aligned}
& C E \text { estimada }_{\text {eda }}=\frac{C E s c p \cdot U s c p}{U s} \\
& K e s_{\text {estimada }}=\frac{K s c p \cdot U s c p}{U s}
\end{aligned}
$$

em que

$\mathrm{CEes}_{\text {estimada }}=$ condutividade elétrica do extrato de saturação estimada a partir da condutividade elétrica da solução do solo obtida com extrator de cápsula, sendo

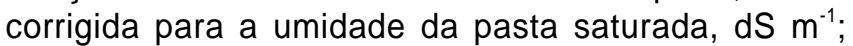
Cescp $=$ condutividade elétrica da solução do solo obtida

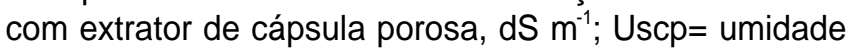
do solo no momento da retirada da solução com o extrator de cápsula porosa, $\mathrm{g} \mathrm{g}^{-1}$; Us= umidade do solo na pasta saturada, $\mathrm{g} \mathrm{g}^{-1}$; Kes estimada $=$ concentração de potássio no extrato de saturação estimada a partir da condutividade elétrica da solução do solo obtida com extrator de cápsula, sendo corrigida para a umidade da pasta saturada, $\mathrm{mmol}_{\mathrm{c}} \mathrm{L}^{-1} ; \mathrm{Kscp}=$ concentração de potássio na solução do solo obtida com extrator de cápsula porosa, $\mathrm{mmol}_{\mathrm{c}} \mathrm{L}^{-1}$.

\section{RESULTADOS E DISCUSSÃO}

A condutividade elétrica e a concentração de potássio na solução do solo obtidas via extrator podem ser utilizados para estimar os valores medidos no extrato saturado, quando corrigidos para a umidade de saturação (Figuras $2 \mathrm{~A}$ e 2B). A correlação desses valores com os medidos no extrato de saturação mostram coeficientes de determinação $\left(R^{2}\right)$ superiores a 0,7 . Isto demonstra que os resultados podem ser considerados satisfatórios, caso seja

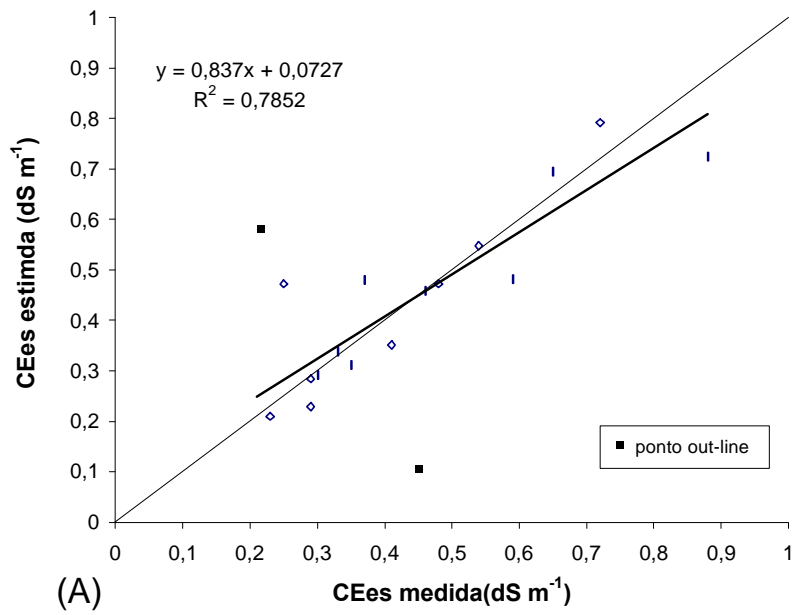

levado em consideração que a determinação da umidade do solo foi realizada utilizando-se tensiômetros, os quais implicam em medida indireta e de precisão relativa. Os valores de condutividade elétrica obtidos com os extratores de cápsulas porosas e corrigidos para a umidade da pasta subestimaram os medidos no extrato da pasta saturada em torno de $16 \%$. Para as concentrações de potássio, a mesma tendência foi observada, sendo a magnitude cerca de $10 \%$. Os pontos denominados de "out-line" não estão inclusos na regressão linear por representarem erros experimentais, entretanto, demonstram que estes erros são inerentes à técnica e foram excluídos por critério visual.

As Figuras $3(A)$ e $3(B)$ ilustram os valores de condutividade elétrica na solução do solo para as frequências de fertirrigação de um e três dias, respectivamente, ao longo do ciclo da cultura monitorada com os extratores. Os valores de condutividade elétrica na solução do solo apresentam-se aquém dos valores recomendados por Burgueño (1996). Possivelmente, este fato pode ser atribuído a um excesso na aplicação de água, o que pode ter acarretado lixiviação de íons com o passar do tempo. Esta hipótese pode ser reforçada considerando que os valores de tensão medidos ao longo do experimento foram pequenos. Entretanto, para solidificar estas afirmações seria necessário a instalação de extratores e tensiômetros a maiores profundidades.

Comportamento semelhante ao da condutividade elétrica foi observado em relação ao potássio na solução do solo (Figuras $4(A)$ e 4(B)). A variação nos níveis de potássio reflete diretamente sobre os valores de condutividade elétrica encontrados para frequência diária, o mesmo não foi observado para frequência de três dias. Possivelmente a maior concentração de potássio na solução, dada a maior frequência de aplicação, ocasionou a substituição deste íon por outros adsorvidos no complexo de troca, em função do tamanho do raio iônico.

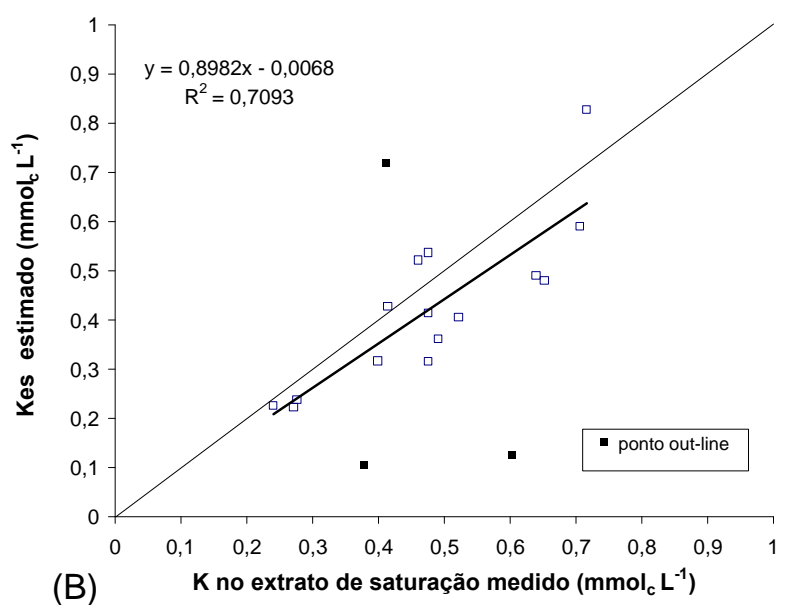

Figura 2 - Correlações entre os valores de : (A) condutividade elétrica e (B) concentração de potássio no extrato de saturação medidos e estimados a partir das soluções obtidas com extrator de cápsula porosa, com correção em função da umidade. 

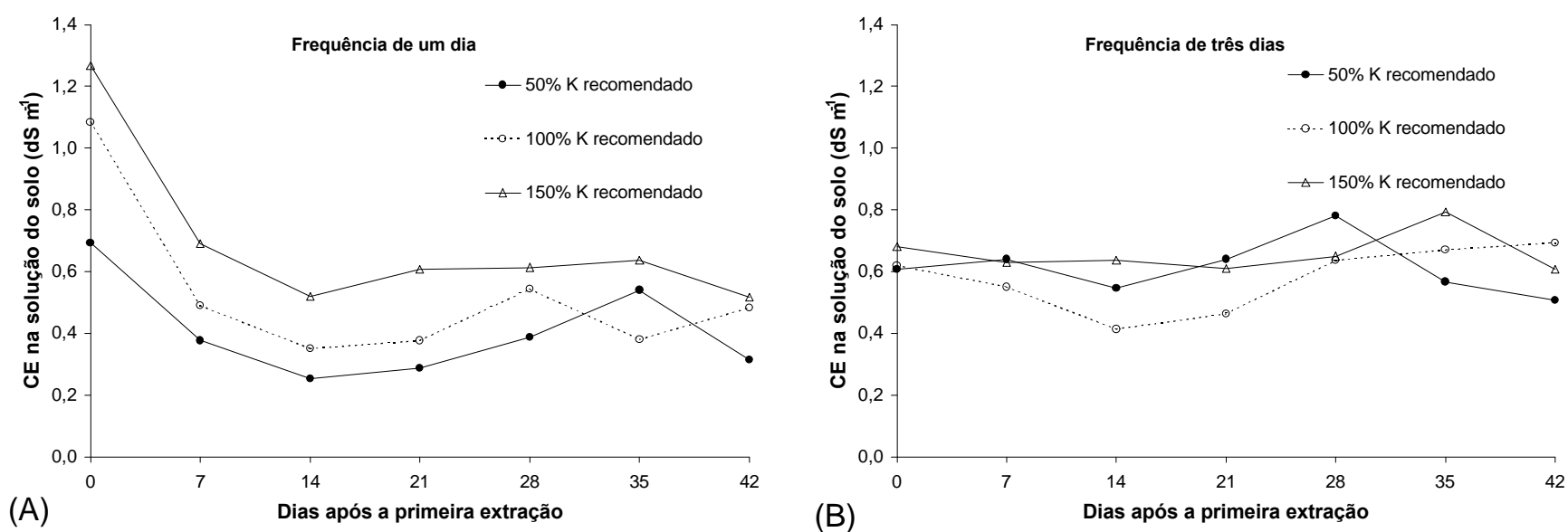

Figura 3 - Variação da condutividade elétrica da solução do solo ao longo do ciclo, para as frequências de irrigação de: (A) 1 dia e (B) 3 dias.
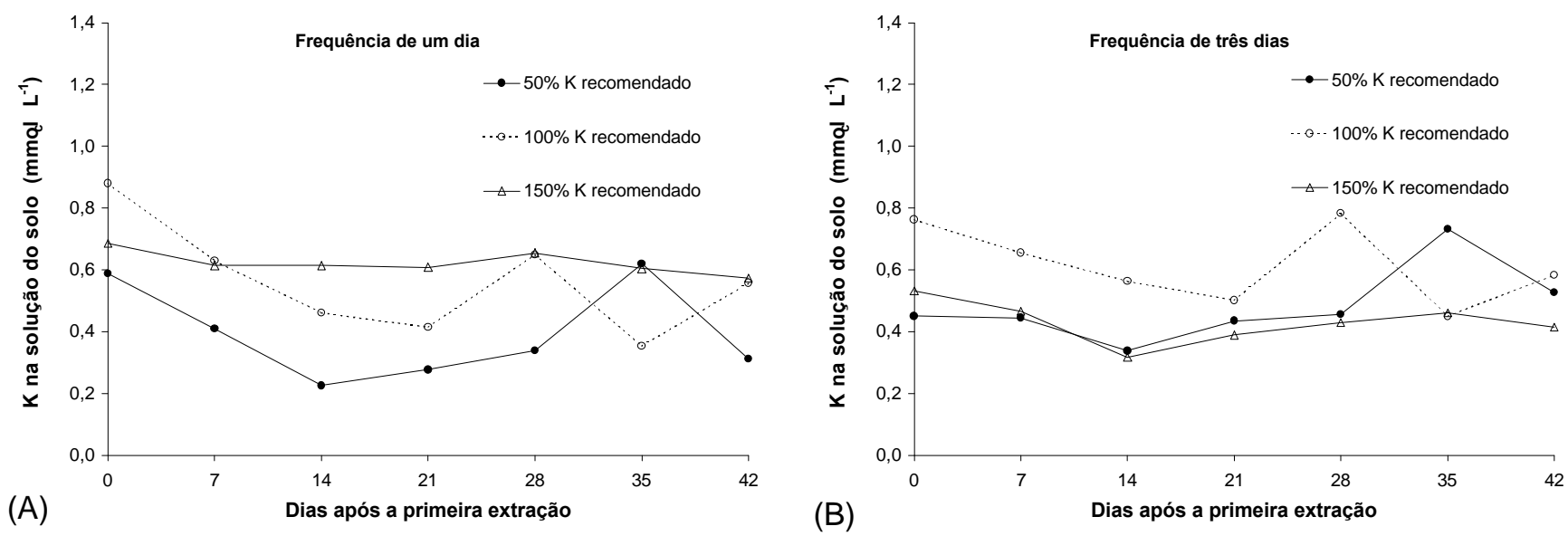

Figura 4 - Variação da concentração de potássio na solução do solo ao longo do ciclo, para as frequências de irrigação de: (A) 1 dia e (B) 3 dias.

Todavia, as pequenas alterações nos valores encontrados parecem não causar efeito diferenciado na nutrição das plantas entre as frequências estudadas, visto que, em ambos os tratamentos os valores encontrados durante o ciclo mostraram-se inferiores aos valores recomendados. Alguns laboratórios, como o Relab den Haan B.V. Research Laboratory com sede na Holanda recomendam como meta uma concentração de $2,2 \mathrm{mmol}_{\mathrm{C}} \mathrm{L}^{-1}$ de potássio na solução do solo para cultura do tomate. Entretanto, foram encontrados concentrações na solução do solo variando entre 0,4 e $0,8 \mathrm{mmol}_{\mathrm{c}} \mathrm{L}^{-1}$. Contudo, para maiores níveis de potássio aplicados houve uma tendência da solução do solo conter concentrações de potássio mais elevadas.

$\mathrm{Na}$ Figura 5 estão demonstrados graficamente os valores médios de condutividade elétrica e potássio na solução do solo para os níveis e frequências estudadas. Os resultados tendem a serem maiores quando a frequência de irrigação foi de três dias para os níveis de 50 e 100\% da recomendação de potássio. Já para o nível de $150 \%$ a freqüência diária proporcionou valores mais elevados. Todavia, as diferenças não parecem ser sensíveis em termos nutricionais para as plantas. Isto pode ter ocorrido em função da excessiva quantidade de água

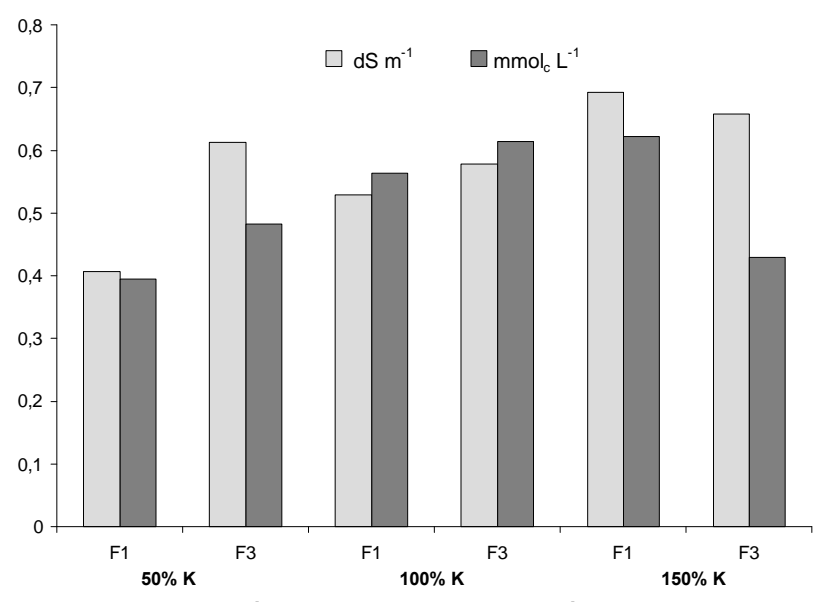

Figura 5 - Valores médios de condutividade elétrica e concentração de potássio na solução do solo para 50, 100 e 150\% da adubação potássica recomendada nas frequências de aplicação de 1 dia (F1) e 3 dias (F3).

aplicada via água de irrigação, a qual pode ter ocasionado remoção de íons para camadas inferiores. Evidencia-se assim, que no estudo da fertirrigação, o manejo racional da irrigação é tão importante quanto as quantidades de fertilizantes a serem adicionados. 
A condutividade elétrica e a concentração de potássio na solução do solo pode ser monitorada ao longo do ciclo da cultura, utilizando-se extratores de cápsula porosa, permitindo a análise da evolução do comportamento da solução. A utilização de tensiômetros para o conhecimento da umidade do solo no momento da extração da solução permite corrigir, com razoável precisão, os valores medidos de condutividade elétrica e concentração de potássio para uma umidade padrão e/ou predeterminada, tornando possível a sua comparação com outros valores obtidos por métodos distintos. Entretanto, a determinação pontual da condutividade elétrica e da concentração de potássio na solução do solo, utilizandose extratores de cápsulas porosas, requer 0 desenvolvimento de mais pesquisas, visto que as regressões obtidas apresentaram coeficientes de determinação considerados apenas razoáveis.

\section{REFERÊNCIAS BIBLIOGRÁFICAS}

AYERS, R.S. Quality of irrigation water. Journal of Irrigation Drainage, v.103, p.135-154, 1977.

AYERS, R.S.; WESTCOT, D.W. Qualidade de água na agricultura. Campina Grande: UFPb, 1991. 218p.

BURGUEÑO, H. La fertirrigacion en cultivos hortícolas com acolchado plástico. Culiacan, 1996. v.1, 45p.
GROVER, B.L.; LAMBORN, R.E. Preparation of porous ceramic cups to be used for extraction of soil water having low solute concentrations. Soil Science Society of America Proceedings, v.34, p.706-708, 1970.

HAINES, W.B. Studies in the physical properties of soil: V. The hysteresis effects in capillary properties and the models of moisture associated therewith. Journal Agronomy Science,v.20, p.97-116, 1930.

MAAS, E.V. Salt tolerance of plants. In: CHRISTIE, B.R. The handbook of plant science in agriculture. Boca Raton: CRC Press, 1984

MAAS, E.V.; HOFFMAN, G.J. Crop salt tolerance: current assessment. Journal of Irrigation and Drainage Division, v.103, p.115-134, 1977.

RICHARDS, L.A. (Ed.) Diagnosis and improvement of saline and alkali soils. Washington: USDA, 1954. 160p. (Handbook,60).

TANJI, K.K.(Ed.) Agricultural salinity assessment and management. New York: ASCE, 1990. 610p. (Manuals and Reports of Engineering Pratices, 71).

TRANI, P.E.; NAGAI, H.; PASSOS, F.A. Tomate (estaqueado). In: RAIJ, B. van; CANTARELLA, H.; QUAGGIO, J.A.; FURLANI, A.M.C. Recomendações de adubação e calagem para o Estado de São Paulo. Campinas: IAC, 1996. 184p.

Recebido em 22.12.99 